\title{
Primary small-cell carcinoma of the palate - the second case report worldwide
}

Agnieszka Kozak-Rusinek ${ }^{1}$, Radzisław Kordek², Jozef Kozak ${ }^{3}$, Marcin Kozakiewicz ${ }^{1}$

\author{
1Department of Maxillofacial Surgery, Medical University of Lodz, Lodz, Poland \\ 2Department of Pathology, Medical University of Lodz, Lodz, Poland \\ ${ }^{3}$ Department of Thoracic Surgery and Respiratory Rehabilitation, Medical University \\ of Lodz, Lodz, Poland
}

Submitted: 12 July 2015

Accepted: 28 July 2015

Arch Med Sci 2017; 13, 6: 1504-1506

DOI: 10.5114/aoms.2016.61977

Copyright $\odot 2016$ Termedia \& Banach

Extrapulmonary small-cell carcinoma (EPSCC) accounts for $0.1-0.4 \%$ of all malignancies and represents $2.5-4 \%$ of all cases of small cell carcinoma [1-5].

The most common anatomical sites for EPSCC are gastrointestinal (23-36\%), genitourinary (20-28\%), head and neck (11-17\%), gynecological organs (11\%), from unknown primary sites (13-31\%), and other sites (4\%) [4]. In the head and neck regions, the most common site were the larynx, salivary glands, submandibular region, nasal cavity, paranasal sinuses, pharynx, thyroid gland and tongue [5-11].

The palate location has been described only by Song et al. [1]. To our knowledge this is the second case report of a patient with EPSCC of the palate in the literature.

Excision of the pulmonary primary site is essential for definition of EPSCC. The differentiation between primary and metastatic EPSCC is a clinical challenge. Currently there is no standard guideline for EPSCC treatment because of its rare occurrence and limited experience in its management. We present a case of EPSCC of the palate after pulmonary origin was excluded.

A 51-year-old female patient was admitted to the Department of Maxillofacial Surgery due to a plum-sized, tender tumor of the hard palate fixed to the underlying tissues. A computed tomography (CT) scan examination diagnosed a $3.6 \times 2.1 \times 1.5 \mathrm{~cm}$ mass destroying partially the hard palate of the right maxilla as well as neck lymphadenopathy of both sites. Radiological examination and CT of the chest revealed a small tumor in the left lung, and ultrasonography examination of the abdomen showed no further metastases.

Biopsy of the palate tumor was performed. The pathology report revealed small-cell carcinoma (SCC). Immunohistochemical staining was positive for cluster of differentiation 56 glycoprotein (CD56) as well as EMA, S100, CK AE1/AE3. Ki-67 > 70\%. CK20, MART1, p63 and chromogranin $A$ were negative.

The patient underwent maxillectomy with a temporalis myofascial flap (TMF) reconstruction of the palate. Furthermore, selective neck dissection (SND) on the right side was performed.

The postoperative pathology reports were compatible with the biopsy outcome. The SCC was diagnosed and pulmonary origin was suspected (Figure 1). Positron emission tomography-computed tomography (PET-CT) revealed a tumor in the left upper lobe of the lung (Figure 2). The patient

\author{
Corresponding author: \\ Agnieszka Kozak-Rusinek \\ Department \\ of Maxillofacial Surgery \\ Medical University of Lodz \\ 113 Żeromskiego St \\ 90-549 Lodz, Poland \\ Phone: +48 504226775 \\ E-mail: agnieszka.kozak@ \\ umed.lodz.pl
}




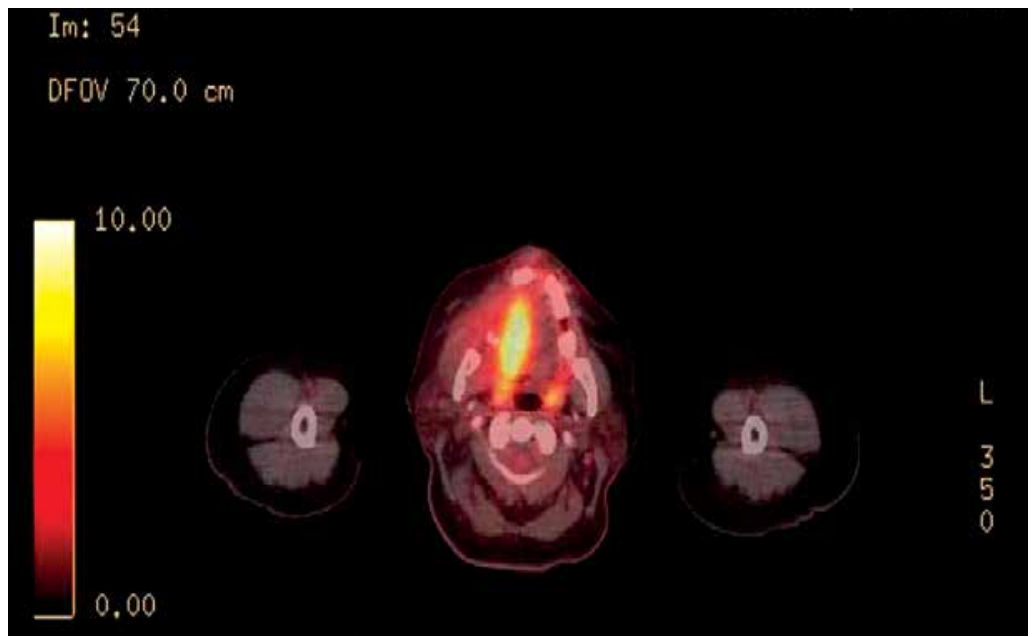

Figure 1. Positron emission tomography-computed tomography view of the area after maxillectomy due to smallcell carcinoma of the hard palate

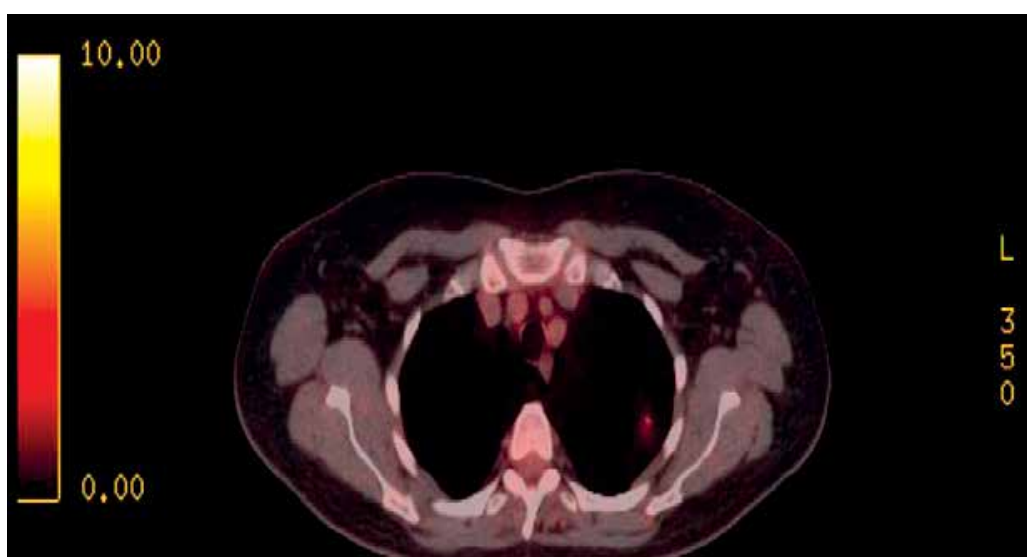

Figure 2. Positron emission tomography-computed tomography view of tumor in the left upper lobe of the lungbefore wedge resection

was transferred to the Department of Thoracic Surgery and Respiratory Rehabilitation, where wedge resection and intraoperative frozen section examination was done. Surprisingly, the examination of the lung tumor showed no malignancy. Extrathoracic location of SCC was established, and the patient was sent to the Department of Oncology, where she received adjuvant chemo-radiotherapy typical for SCC.

Outpatient follow-up was performed at regular intervals. After a year, no recurrence is observed.

Duguid and Kennedy first described in 1930 two cases of mediastinal oat cell tumor where autopsy failed to reveal pulmonary involvement [11]. The EPSCC resembles its pulmonary counterpart with regard to morphology, immunohistochemistry and electron microscopy features.

It derives from pluripotential stem cells that develop neuroendocrine features. It is characterized by round to spindle-shaped small cells with dense nuclei, inconspicuous nucleoli, and sparse cytoplasm under light microscopy. The SCC has a high mitotic index, grows in sheets and trabec- ular patterns, and may contain areas of necrosis. On electron microscopy, neurosecretory granules can be identified.

There is increasing evidence that EPSCC can arise from pluripotent basilar cells capable of divergent differentiation with the consequence that the neuroendocrine phenotype arises as a transdifferentiation phenomenon in progression of an organ-specific carcinoma [12].

Although a rare diagnosis, EPSCC is an important radiological consideration due to its aggressive nature. Advanced locoregional disease, the presence of lymphadenopathy even with small tumors and distant metastasis were all common radiological findings with these tumors [13].

Immunohistochemical markers such as cytokeratin, neuron-specific enolase (NSE), epithelial membrane antigen (EMA), CEA, chromogranin A, and synaptophysin are helpful for the diagnosis [8, 14].

In our case the tumor was immunohistochemically negative for neuron-specific chromogranin A, which seems unusual for neuroendocrine derived SCC; however, there have been several reports 
showing negative immunostaining of chromogranin A in EPSCC [5].

Thyroid transcription factor 1 (TTF-1) is useful for differentiating SCC from other types of neuroendocrine tumors because EPSCC cells are generally positive for TTF-1 while other neuroendocrine tumors are not [4].

The EPSCC was usually found in patients at 6070 years of age. Smoking and alcohol have been identified as risk factors [10]. Some authors suggested that its etiological factors are more likely to be genetic and developmental rather than environmental [2].

The differential diagnosis includes metastatic SCC, other types of neuroendocrine tumors, Merkel cell tumors, metastatic melanoma, lymphoma and poorly differentiated carcinoma.

There is no established system for EPSCC staging. Most clinicians have adopted the two-stage classification used for SCC: the limited stage (LD) and extensive stage (ED).

The proportion of patients with LD in head and neck tumors is $84 \%$.

There is no standard guideline for EPSCC treatment. The prognosis is poor and 3-year survival is $30 \%$ for LD and $10 \%$ for ED [2]. The 5 -year survival rate was $11-13 \%$ [4]. The most common sites for distant metastases are lungs, liver and bones. Brain metastases are less common in EPSCC compared to SCC [4], and some authors do not recommend use of palliative brain irradiation (PCI) [15] except in patients with a primary location in the head and neck region. Because of the high tendency of local recurrence and metastatic spread, multimodality therapy is increasingly applied. Galanis et al. reported the results to be particularly disappointing when locoregional extension or regional lymph node involvement were present [10]. Radical surgery could play a role in those cases in which a complete resection can be achieved with minimal morbidity. The chemotherapeutic regimens are similar to those used in SCC (combination of cisplatin + etoposide, cisplatin + irinotecan with a response rate of $69 \%$ ) $[6,8]$. Radiotherapy also has an effective role with a dose of at least 50 Gy in 2 Gy fractions [3]. Although outcomes for EPSCC remain poor, both surgery and radiation have been shown to significantly improve median 5- and 10-year survival rates [16]. Ochsenreither et al. reported longterm survival with multimodal treatment including surgery plus chemo- or chemoradiotherapy [12].

In spite of treatment, the median survival is 8-16 months $[1,4,5,10]$.

The EPSCC originating from the head and neck have a more favorable outcome than other sites, partly attributed to early detection and intensive treatment.

In conclusion, primary palate SCC is rare. Complete excision and chemoradiotherapy is recom- mended. The PET-CT is useful for establishing diagnosis and staging of the disease. Standard guidelines should be established for treatment of EPSCC.

\section{Acknowledgments}

Grant: 502-03/5-061-02/502-54-122.

\section{Conflict of interest}

The authors declare no conflict of interest.

\section{References}

1. Song Y, Lin Z, Chen L, Wu G. Primary small-cell carcinoma of the palate with Cushing's syndrome: a case report. Case Rep Oncol Med Epub 2012; 2012: 539306.

2. Wong YN, Jack RH, Mak V, Henrik M, Davies EA. The epidemiology and survival of extrapulmonary small cell carcinoma in South East England, 1970-2004. BMC Cancer 2009; 9: 209.

3. Brennan SM, Gregory DL, Stillie A, Herschtal A, Mac Manus M, Ball DL. Should extrapulmonary small cell cancer be managed like small cell lung cancer? Cancer 2010; 116: 888-9.

4. Lu CH, Chou WC, Chen CC, Lin JT, Chan CH, Lee KD. Extrapulmonary small cell carcinoma: a review. J Int Med T 2009; 20: 294-300.

5. Nakahara S, Takemoto N, Inohara H. Small cell carcinoma of the larynx treated by concurrent chemoradiotherapy: a case report. Case Rep Otolaryngol 2012; 2012 316165.

6. Walenkamp AM, Sonke GS, Sleijfer DT. Clinical and therapeutic aspects of extrapulmonary small cell carcinoma. Cancer Treat Rev 2009; 35: 228-36.

7. Aydil U, Kızıl Y, Bakkal FK, Köybaşıoğlu A, Uslu S. Neoplasms of the hard palate. J Oral Maxillofac Surg 2014; 72: 619-26.

8. Lin YC, Wu HP, Tzeng JE. Small-cell undifferentiated carcinoma of the submandibular gland: an extremely rare extrapulmonary site. Am J Otolaryngol 2005; 26: 60-3.

9. Renner G. Small cell carcinoma of the head and neck a review. Semin Oncol 2007; 34: 3-14.

10. Galanis E, Frytak S, Lloyd RV. Extrapulmonary small cell carcinoma. Cancer 1997; 79: 1729-36.

11. Duguid J, Kennedy A. Oat cell tumors of mediastinal glands. J Pathol Bacteriol 1930; 33: 93-9.

12. Ochsenreither S, Marnitz-Schultze S, Schneider A, et al. Extrapulmonary small cell carcinoma (EPSCC): 10 years' multi-disciplinary experience AT Charite. Anticancer Res 2009; 29: 3411-6.

13. Joyce EA, Kavanagh J, Beddy P. Imaging features of extra-pulmonary small cell carcinoma. Clin Radiol 2013; 68: 953-61.

14. Frazier SR, Kaplan PA, Loy TS. The pathology of extrapulmonary small cell carcinoma. Semin Oncol 2007; 34 30-8.

15. Naidoo J, Teo MY, Deady S, Comber H, Calvert P. Should patients with extrapulmonary small-cell carcinoma receive prophylactic cranial irradiation? J Thorac Oncol 2013; 8: 1215-21.

16. Grossman RA, Pedroso FE, Byrne MM, Koniaris LG, Misra S. Does surgery or radiation therpy impact survivor for patients with extrapulmoary small cell cancers? J Surg Oncol 2011; 104: 604-12. 